\title{
Critical supervision for the human services: A social model to promote learning and value-based practice
}

\author{
Carolyn Noble, Mel Grey and Lou Johnston \\ Jessica Kingsley Press, 2016 \\ ISBN 978-1-84905-589, pp. 285, paperback, NZD54
}

$\mathrm{N}$ oble, Grey, and Johnston have produced a well written and well researched text which explores professional supervision from a critical perspective. The elements of critical supervision, as summarised by the authors, are: transformative, pursu[ing] a social justice agenda, anti-oppressive, culturally relevant, built-on resistance, built-on critical pedagogy, relational and work[ing] best within a learning organisation (p. 144).

The book takes the reader on journey. Chapter One sets the scene with an overview of contemporary approaches to conventional supervision and leads the way to the authors' description and understanding of supervision from a critical perspective. Applying critical theory to supervision, they argue, moves supervision "to a transformative orientation informed by social justice and human rights" (p. 36). The following three chapters place human service practice (and supervision) in broad perspective and consider the impact of contemporary contexts. Beginning with the influence of the global context, chapter two explores, among other things, neoliberalism, welfare austerity and service user participation. The contextual theme is continued in the following two chapters where organisational and workplace context and the professional practice context are examined.

The core concepts of a critical perspective is the focus of Chapter Five and the authors present a very useful description of the five central concepts of a critical perspective. Identifying these as critical reflection, critical thinking, critical analysis, critical theory and critical perspectives, the authors consider each in turn and provide helpful critique which identifies both the similarities and the important differences between these concepts. Chapter Six completes this group of theoretical chapters by presenting critical pedagogy as the appropriate framework through which to develop a critical perspective which, in turn, enables critical supervision to support the development of transformative learning and critical practitioners.

The final chapters of the book are dedicated to supervision practice. Beginning with "foundational principles" the authors link the discussion from preceding chapters to their critical approach to supervision. Chapter Eight provides a guide to establishing critical supervision and is both practical and informative. Of particular note in this chapter is discussion which concerns the supervision relationship, supervision conversations and power. The tool box of critical supervision, chapter nine, presents useful prompts to shape and develop the sorts of "difficult and challenging questions" which are necessary to "pose and answer" (p. 182). The narrative toolbox is introduced where narrative (oral or written) is recognised as a source for analysis and meaning-making. The authors make the point however, that it is not the tools which determine their criticality but rather the way in which they are used. Chapter Ten draws from the preceding chapters and presents a four-step "critical process." 
What is significant here is that the authors present the critical process as one which can be applied outside of the supervision arrangement. It is, they say, applicable to "other practice, service planning and organisational learning activities" (p. 198) and informal conversations outside of supervision. The final chapter of the book presents five scenarios from practice to demonstrate the process in action.

Whilst it is not until Chapter Seven that the book settles to focus specifically on critical supervision and what that looks like in practice, great care has been taken to assist the reader to engage with, follow and make sense of the content. Each chapter has an introduction and a conclusion which both summarise the key ideas and argument from that chapter, and link those ideas to the chapter ahead or, where relevant, those preceding. These connections are also peppered throughout the text. The book is liberally illustrated by figures (9) and tables (25) which are also referred to throughout the book, making connections back and forth. Not only are suggestions made for how these tables and figures may assist readers' comprehension, but suggestions are also given for how they may be used practically to inform and shape practice. Finally, the relevance of each chapter to supervision, which is the central focus of the book, is maintained through a series of questions interspersed throughout the text. These questions serve to guide and redirect the readers' thoughts to actual supervision arrangements and experiences. The authors explain this as being congruent with the topic in hand "questions, questions, questions ... this is what a critical perspective is about" (p. 105). The book concludes with a comprehensive, 10-page glossary of terms.

Having noted a gap, Noble et al. have, in my opinion, successfully filled it with this addition to the supervision literature. This book challenges all human service practitioners to really consider what it means to claim social justice and human rights as basic tenets of practice, but more importantly, it provides a critical framework to shape and develop that transformative practice. The book is intended for a broad audience being presented as relevant to those who are involved in a wide range of human services, who occupy diverse roles and who represent a range of professions. 